\title{
The 6-31B(d) Basis Set and the BMC-QCISD and BMC-CCSD Multi-Coefficient Correlation Methods
}

\author{
Benjamin J. Lynch, Yan Zhao, and Donald G. Truhlar \\ Department of Chemistry and Supercomputer Institute, University of Minnesota, \\ Minneapolis, MN 55455-0431
}

\begin{abstract}
Three new multi-coefficient correlation methods (MCCMs) called BMC-QCISD, BMC-CCSD, and BMC-CCSD-C are optimized against 274 data that include atomization energies, electron affinities, ionization potentials, and reaction barrier heights. A new basis set called 6-31B(d) is developed and used as part of the new methods.

BMC-QCISD has mean unsigned errors in calculating atomization energies per bond and barrier heights of $0.49 \mathrm{kcal} / \mathrm{mol}$ and $0.80 \mathrm{kcal} / \mathrm{mol}$, respectively. BMC-CCSD has mean unsigned errors of 0.42 and $0.71 \mathrm{kcal} / \mathrm{mol}$ for the same two quantities. BMC-CCSD-C is an equally-effective variant of BMC-CCSD that employs Cartesian rather than spherical harmonic basis sets. The mean unsigned error of BMC-CCSD or BMC-CCSD-C for atomization energies, barrier heights, ionization potentials, and electron affinities is $22 \%$ lower than G3SX(MP2) at an order of magnitude less cost for gradients for molecules with 9-13 atoms, and it scales better ( $N^{6}$ vs. $N^{7}$, where $N$ is the number of atoms) when the size of the molecule is increased.
\end{abstract}




\section{Introduction}

Multi-coefficient correlation methods ${ }^{1-6}$ (MCCMs) have proven to be a very efficient means for the computation of thermochemical properties. MCCMs use a linear combination of $a b$ initio wave function methods to extrapolate to the exact nonrelativistic Born-Oppenhiemer solution to the Schrödinger equation. Many MCCM methods, such as multi-coefficient QCISD ${ }^{6}$ (MC-QCISD/3), multi-coefficient G3 ${ }^{6}$ (MCG3/3), G3-Scaled ${ }^{5,6}$ (G3S/3), G3S-Extended ${ }^{7}$ (G3SX), and reduced-order G3SX (G3SX(MP2) and G3SX(MP3)), use a large one-electron basis set for uncorrelated and less-correlated components (Hartree-Fock (HF) and Møller-Plesset (MP) second-order perturbation theory $^{8}$ (MP2), respectively) and a small one-electron basis set for components that include a large amount of electron correlation (quadratic configuration interaction with single and double excitations ${ }^{9}$ (QCISD), and QCISD with quasiperturbative triples, $\left.{ }^{9} \mathrm{QCISD}(\mathrm{T})\right)$.

Current MCCM methods utilize previously constructed basis sets, and simultaneously extrapolate to full electron correlation and a complete one-electron basis set. Although larger basis sets usually give more accurate energies in single-level approaches, there is no guarantee that a linear combination of energies will improve as

one improves the basis sets. Previous studies ${ }^{10}$ have noted that an arbitrary improvement of one of the basis sets in a MCCM can lead to an inferior method, even when the extrapolation coefficients are re-optimized for the new basis set. In fact, this phenomenon was pointed out ${ }^{11}$ years ago in the context of scaling all correlation energy (SAC), where it was emphasized that a basis set useful for such extrapolation must be “correlation balanced.” With this in mind, in the present article, we developed three new 
MCCM methods that employ a new basis set designed to have optimal extrapolation properties.

Previous studies ${ }^{6,12}$ have show that the QCISD level of electron correlation is a minimal level for achieving reliable extrapolations of the electron correlation energy, and this work led to the development of MC-QCISD. ${ }^{12}$ Extrapolation with lower levels such as MP2 and fourth-order MP perturbation theory with single double and quadruple

excitations (MP4(SDQ)) is more accurate and less expensive than not extrapolating, 2,6,13 but it is not as reliable as extrapolation methods that include at least one calculation with QCISD or better. ${ }^{6,12,14}$ MC-QCISD has been shown to be a highly efficient MCCM method, and this is why it is the starting point of the new method developed here. However, it is well known that there are some cases ${ }^{15-18}$ where coupled cluster theory with single and double excitations (CCSD) performs significantly better than QCISD. Therefore we also report a version of the theory in which the coefficients are optimized for CCSD instead of QCISD.

Section 2 discusses the experimental database used, Section 3 describes the optimization of the new method and basis set, Section 4 gives the results and discussion, and Section 5 is a summary.

\section{Methods and Experimental Database}

The theoretical methods used in the present study include HF, MP2, MP fourthorder perturbation theory with double and quadruple excitations ${ }^{19}$ (MP4(DQ)) or with single, double, and quadruple excitations ${ }^{19}$ (MP4(SDQ)), coupled-cluster theory with singles and doubles (CCSD), ${ }^{9,20}$ CCSD with quasiperturbative connected triples ${ }^{20}$ $(\mathrm{CCSD}(\mathrm{T}))$, and full configuration interaction ${ }^{21,22}$ (FCI). For all correlated $a b$ initio 
methods, the core orbitals are doubly occupied in all configurations. For full CI calculations, all virtual orbitals are included. FCI calculations were performed with MOLPRO, ${ }^{23}$ and the remainder of the calculations were performed with GAUSSIAN98 ${ }^{24}$ and GAUSSIAN03. ${ }^{25}$

In addition to the new 6-31B(d) basis set described in section 3, this paper uses the following other basis sets: $6-31 \mathrm{G}(\mathrm{d}),{ }^{19}$ 6-31G(2df,p), ${ }^{19} \mathrm{G} 3 \mathrm{Large},{ }^{26} \mathrm{MG} 3,{ }^{4,27} \mathrm{MG} 3 \mathrm{~S},{ }^{10}$ and G3XLarge. ${ }^{7}$

A new test set was created for the present work. It consists of 273 data and is named Database/4. We optimized the basis sets and MCCM coefficients for this paper using Database/4HM which is identical to Database/4 except that it also includes the electron affinity for $H$. It contains 160 atomization energies (AEs), 36 electron affinities (EAs), 36 ionization potentials (IPs), and 42 barrier heights (BHs). We note than 177 data are from Database $/ 3,{ }^{6}$ and the 97 new data are described below. All data in Database/4 are zero-point exclusive, i.e., zero-point contributions to the energy have been removed from the experimental values so that the values in the database can be directly compared to calculated theoretical electronic energies (including nuclear repulsion). All data in Database/4 are for main group elements; transition metals are not considered.

For electron affinities and ionization potentials, we start with the experimental IP or EA. Zero-point-exclusive EAs and IPs are determined by removing the ZPE calculated using mPW1PW91/MG3 frequencies scaled ${ }^{10}$ by 0.9758 . The zero-pointexclusive EAs and IPs in Database/4 are listed in supporting information. Database/4 includes 13 IPs from Database/3 and new experimental IPs for $\mathrm{Li}^{28} \mathrm{Be}^{28}{ }^{28},{ }^{28} \mathrm{~N},{ }^{28} \mathrm{~F},{ }^{28}$ $\mathrm{Na},{ }^{28} \mathrm{Mg},{ }^{28} \mathrm{Al},{ }^{28} \mathrm{Cl},{ }^{28} \mathrm{AlO},{ }^{29} \mathrm{NH}_{3},{ }^{29} \mathrm{CN},{ }^{30} \mathrm{Na}_{2},{ }^{29} \mathrm{O}_{3},{ }^{29} \mathrm{CF},{ }^{29} \mathrm{CH}_{3},{ }^{29} \mathrm{Al}_{2},{ }^{31} \mathrm{SiH},{ }^{29} \mathrm{FO},{ }^{32}$ 
$\mathrm{PO}^{29} \mathrm{AlF}^{33} \mathrm{NaLi}^{34}$ and $\mathrm{MgCl}^{35}$ Database/4 includes 13 EAs from Database/3 and new experimental EAs for $\mathrm{H},{ }^{36} \mathrm{Li},{ }^{36} \mathrm{~B},{ }^{36} \mathrm{~F},{ }^{36} \mathrm{Na},{ }^{36} \mathrm{Al},{ }^{36} \mathrm{AlO},{ }^{37} \mathrm{NH},{ }^{36} \mathrm{CN},{ }^{36} \mathrm{CH},{ }^{36} \mathrm{CH}_{2},{ }^{36}$ $\mathrm{O}_{3},{ }^{36} \mathrm{LiCl}^{36} \mathrm{NaF}^{36} \mathrm{SiH},{ }^{36} \mathrm{MgCl}^{36} \mathrm{Na}_{2},{ }^{36} \mathrm{HNO},{ }^{36} \mathrm{MgH}^{36} \mathrm{Al}_{3},{ }^{38} \mathrm{FO},{ }^{36} \mathrm{PO},{ }^{36}$ and $\mathrm{BeH} .{ }^{36}$ We note that $\mathrm{PO}^{-}$is described as a ground state singlet elsewhere; ${ }^{36}$ however with careful SCF convergence one will predict that it is a ground state triplet, which agrees with experiment. $^{39}$ All 42 barrier heights used in Database/4 are unchanged from Database/3.

We include the 109 atomization energies from Database/3 and the atomization energy for the following 51 additional systems: $\mathrm{LiH},{ }^{28} \mathrm{BeH},{ }^{30} \mathrm{Li}_{2},{ }^{30} \mathrm{BeLi},{ }^{40} \mathrm{BH}_{3},{ }^{35} \mathrm{~B}_{2},{ }^{41}$ $\mathrm{LiO},{ }^{30} \mathrm{BC},{ }^{42} \mathrm{NaH},{ }^{43} \mathrm{LiF},{ }^{30} \mathrm{LiOH},{ }^{35} \mathrm{BeO},{ }^{44} \mathrm{MgH},{ }^{30} \mathrm{BeF},{ }^{45} \mathrm{BeOH},{ }^{46} \mathrm{BO},{ }^{47} \mathrm{AlH},{ }^{48} \mathrm{BF},{ }^{30}$ $\mathrm{FO},{ }^{35} \mathrm{LiCl}_{,}{ }^{30} \mathrm{NaF},{ }^{35} \mathrm{NaOH},{ }^{44} \mathrm{MgO},{ }^{44} \mathrm{PC},{ }^{49} \mathrm{AlO},{ }^{50} \mathrm{BeCl}^{35} \mathrm{MgF}^{35} \mathrm{MgOH}^{51}{ }^{5} \mathrm{~N}_{2} \mathrm{O},{ }^{28}$ $\mathrm{HCP},{ }^{52} \mathrm{Na}_{2},{ }^{35} \mathrm{AlF},{ }^{35} \mathrm{NaLiO},{ }^{44} \mathrm{BeF}_{2},{ }^{35} \mathrm{Be}(\mathrm{OH})_{2},{ }^{44} \mathrm{NO}_{2},{ }^{28} \mathrm{PO},{ }^{35}\left(\mathrm{C}_{2} \mathrm{H}_{4}\right) \mathrm{NH}^{28}{ }^{28} \mathrm{O}_{3},{ }^{28}$ $\mathrm{NaCN},{ }^{35} \mathrm{NCCN},{ }^{28} \mathrm{Al}_{2},{ }^{53} \mathrm{NaCl},{ }^{35} \mathrm{MgS},{ }^{54} \mathrm{MgCl},{ }^{55} \mathrm{PO}_{2},{ }^{56} \mathrm{ClNO}^{28} \mathrm{CH}_{3} \mathrm{CONH}_{2},{ }^{28}$ $\mathrm{ClNO}_{2},{ }^{35} \mathrm{BFCl}_{2},{ }^{35}$ and $\mathrm{SF}_{6} \cdot{ }^{27}$

When available, the starting $D_{0}$ or $D_{\mathrm{e}}$ value is taken from the references in the previous paragraph; in most of the remaining cases we begin with the experimental $\Delta H_{\mathrm{f}, 298}^{\mathrm{o}}$ and use the procedure described elsewhere ${ }^{2}$ to obtain the zero-point exclusive atomization energy $\left(D_{\mathrm{e}}\right)$. The $D_{\mathrm{e}}$ for a few systems were determined in system-specific ways, as follows: We updated our $D_{\mathrm{e}}$ for $\mathrm{CH}_{2}\left({ }^{3} \mathrm{~B}_{1}\right)$ from the experimental ${ }^{57} D_{0}$ of 753.3 $\mathrm{kJ} / \mathrm{mol}$ and the anharmonic $\mathrm{ZPE} \mathrm{E}^{58}$ of $3736.4 \mathrm{~cm}^{-1}$ giving a $D_{\mathrm{e}}$ of $190.72 \mathrm{kcal} / \mathrm{mol}$. We obtained an updated $D_{\mathrm{e}}$ for $\mathrm{CH}_{2}\left({ }^{1} \mathrm{~A}_{1}\right)$ of $181.37 \mathrm{kcal} / \mathrm{mol}$ from the $D_{\mathrm{e}}$ of $\mathrm{CH}_{2}\left({ }^{3} \mathrm{~B}_{1}\right)$, the experimental singlet-triplet splitting $\left(T_{0}\right)$ of $3147 \mathrm{~cm}^{-1},{ }^{59}$ and the anharmonic ZPE ${ }^{58}$ of 
$3612.0 \mathrm{~cm}^{-1}$ for $\mathrm{CH}_{2}\left({ }^{1} \mathrm{~A}_{1}\right)$. We updated the $D_{\mathrm{e}}$ for $\mathrm{NO}$ using the experimental heat of formation, ${ }^{35}$ thermal corrections calculated with MP2/cc-pVDZ frequencies scaled by 0.979, and the experimental zero-point energy ${ }^{30}$ of $2.71 \mathrm{kcal} / \mathrm{mol}$ to give a $D_{\mathrm{e}}$ of 152.05 $\mathrm{kcal} / \mathrm{mol}$. We updated the $D_{\mathrm{e}}$ for $\mathrm{C}_{2} \mathrm{~F}_{4}$ to be the average of two experiments. ${ }^{35,60}$

To aid in the accurate prediction of $\mathrm{D}_{\mathrm{e}}$ for $\mathrm{CCH}$ and $\mathrm{MgCl}$ we optimized a general scaling factor for fundamental frequencies to obtain accurate ZPEs. Table 1 gives the anharmonic $\mathrm{ZPE}^{2}$ and the ZPE predicted by four other methods. The scaling factor for MP2/cc-pVDZ ZPE was found in a previous study ${ }^{2}$ and has been used for many data in Database/4. However, for some systems, especially those with high spin contamination, the MP2/cc-pVDZ frequencies are much higher than experiment. Therefore, we optimized a scaling factor that relates experimental fundamental frequencies $^{2}$ to the anharmonic ZPE. The scaling factor we obtain is 1.021 . Using this new scale factor and the experimental fundamental frequencies ${ }^{35}$ for $\mathrm{CCH}$, we obtain an improved $D_{\mathrm{e}}$ of $265.13 \mathrm{kcal} / \mathrm{mol}$ to replace the previous value of $267.83 \mathrm{kcal} / \mathrm{mol}$. For $\mathrm{MgCl}$, we use the experimental ${ }^{55} D_{\mathrm{o}}$ and the fundamental frequency to obtain a $D_{\mathrm{e}}$ of 76.44 .

Our calculations explicitly include spin-orbit coupling for all calculations where it is not zero by symmetry; these atoms, ions, and molecules found in Table 2. (Therefore, spin-orbit contributions are not removed from the database values.) The spin-orbit coupling values in Table 2 come from previous collections. ${ }^{2,30,61}$ All values tabulated are the stabilization of the ground state using the Russell-Saunders scheme.

The average number of bonds for molecules in the atomization database of Database/4 is called $N_{\text {bonds }}$ and equals 3.775 where we count double and triple bonds as 
one bond, not 2 or 3 . In order to make average errors more comparable over various databases and in order to provide the reader with a more physical characterization of the accuracy of the results, we compare the mean unsigned error per bond (MUEPB) by dividing the mean unsigned error (MUE) in atomization energies by the mean number of bonds.

The complete Database/4 and Database/4HM are given in supporting information and on our Database web site. ${ }^{62}$

\section{Optimization of the New Method}

The structures used here for all systems are geometries optimized by QCISD/MG3. Although we choose to use these geometries for all calculations in this paper, this level of theory is not an intrinsic part of the new method developed here. These geometries were chosen to adequately assess the electronic energies of different methods without the need to embark on a lengthy interpretation of the effect of cancellation of errors that can occur when using lower-level geometries. All results in

this article, including those obtained with G3SX, G3SX(MP3), and G3SX(MP2), will use the QCISD/MG3 geometries. We use the convenient shorthand notation //QM when necessary to specify this geometry to avoid confusion; this is required only for methods that are standardly defined to use other geometries.

In all cases, calculations are based on the lowest-energy geometry (conformation). For example, for $n$-butane we use the trans conformation (not the gauche).

The new methods developed are based on MC-QCISD/3. Figure 1 illustrates the basis sets and levels of theory used in a MC-QCISD/3 calculation. The corresponding energy expression for MC-QCISD is 


$$
\begin{aligned}
& E(\mathrm{MC}-\mathrm{QCISD} / 3)=E(\mathrm{HF} / 6-31 \mathrm{G}(\mathrm{d}))+ \\
& c_{1} \Delta(\mathrm{HF} / \mathrm{MG} 3 \mathrm{~S} \mid 6-31 \mathrm{G}(\mathrm{d}))+c_{2} \Delta(\mathrm{MP} 2 \mid \mathrm{HF} / 6-31 \mathrm{G}(\mathrm{d})) \\
& c_{3} \Delta(\mathrm{MP} 2|\mathrm{HF} / \mathrm{MG} 3 \mathrm{~S}| 6-31 \mathrm{G}(\mathrm{d}))+c_{4} \Delta(\mathrm{QCISD} \mid \mathrm{MP} 2 / 6-31 \mathrm{G}(\mathrm{d}))+E_{\mathrm{SO}}
\end{aligned}
$$

where we use the pipe notation (“|”) introduced elsewhere ${ }^{14}$ to describe the energy differences that are scaled. The new BMC-QCISD method developed here differs from MC-QCISD/3 in three respects. First, it uses a modified extrapolation scheme which scales the MP4(SDQ) energy increment separately, as shown in figure 2. Second, it replaces the MG3S basis with the MG3 basis. Finally, it uses a new basis set named 6-31B(d) in place of 6-31G(d). The energy expression for BMC-QCISD is given in Equation 2:

$$
\begin{aligned}
& E(\mathrm{BMC}-\mathrm{QCISD})=E(\mathrm{HF} / 6-31 \mathrm{~B}(\mathrm{~d}))+ \\
& c_{\mathrm{H}} \Delta(\mathrm{HF} / \mathrm{MG} 3 \mid 6-31 \mathrm{~B}(\mathrm{~d}))+c_{1} \Delta(\mathrm{MP} 2 \mid \mathrm{HF} / 6-31 \mathrm{~B}(\mathrm{~d}))+ \\
& c_{2} \Delta(\mathrm{MP} 2|\mathrm{HF} / \mathrm{MG} 3| 6-31 \mathrm{~B}(\mathrm{~d}))+c_{3} \Delta(\mathrm{MP} 4 \mathrm{SDQ} \mid \mathrm{MP} 2 / 6-31 \mathrm{~B}(\mathrm{~d}))+ \\
& c_{4} \Delta(\mathrm{QCISD} \mid \mathrm{MP} 4 \mathrm{SDQ} / 6-31 \mathrm{~B}(\mathrm{~d}))+E_{\mathrm{SO}}
\end{aligned}
$$

The new method, named BMC-QCISD, uses the same number of extrapolation coefficients as MC-QCISD. The coefficient $c_{\mathrm{H}}$ comes from Equation 3:

$$
c_{\mathrm{H}}=\frac{E_{\mathrm{H}}-E_{\mathrm{H}}[6-31 \mathrm{~B}(\mathrm{~d})]}{E_{\mathrm{H}}[\mathrm{MG}]-E_{\mathrm{H}}[6-31 \mathrm{~B}(\mathrm{~d})]}
$$

where $E_{\mathrm{H}}$ is the energy for hydrogen atom.

The 6-31B(d) basis set is based on 6-31G(d). The basis set exponent for the most diffuse valence function and the polarization function is optimized for each atom. For hydrogen, this means optimizing the most diffuse $s$-function. For the remaining atoms, this meant changing the exponent of the most diffuse $s p$-set and the exponent of the $d$ 
function for each atom. The objective function minimized is a weighted sum of the squares of the errors for the 274 data described in Section 2, and is:

$$
\begin{gathered}
U F=\sqrt{\sum_{i=1}^{274} w_{i}\left(E_{\text {calc }}-E_{\exp }\right)^{2}} \\
w_{i}=\frac{1}{6 N_{\mathrm{EA}}} \text { for electron affinities } \\
w_{i}=\frac{1}{6 N_{\mathrm{IP}}} \text { for ionization potentials } \\
w_{i}=\frac{1}{3 N_{\mathrm{BH}}} \text { for barrier heights } \\
w_{i}=\frac{1}{3 N_{\mathrm{AE}} \bar{N}_{\text {bonds }}^{2}} \text { for atomization energies }
\end{gathered}
$$

where $N_{\mathrm{EA}}$ is the number of electron affinity data, $N_{\mathrm{IP}}$ is the number of ionization potential data, $N_{\mathrm{BH}}$ is the number of barrier height data, and $N_{\mathrm{AE}}$ is the number of atomization energy data. Thus the objective function places $33 \%$ weight on bond energies, $33 \%$ on barrier heights, and $17 \%$ each on ionization potentials and electron affinities. The optimized basis functions for the 6-31B(d) basis set are listed in Table 3, and the scaling coefficients are in Table 4. The exponents for the basis functions were optimized simultaneously with the four extrapolation coefficients. The basis functions were optimized using a genetic algorithm, and the optimal extrapolation coefficients $\left(c_{1}\right.$, $c_{2}, c_{3}, c_{4}$ ) were found at each step from the solution to the system of linear equations that minimize the error expression. Each basis function was allowed to vary by as much as a factor of 2 from its corresponding coefficient in the 6-31G(d) basis set. After we were 
satisfied that the genetic algorithm was converged, the parameters were varied to confirm that it was a minimum.

A very similar theory to QCISD $^{9}$ is CCSD. CCSD ${ }^{63,64}$ includes all of the interactions of QCISD and a few additional interactions that have a minimal effect on the cost. $^{65}$ In fact, QCISD may be viewed as an approximation to CCSD. A main advantage of QCISD over CCSD in previous work was the wider availability of analytic gradients for QCISD than for CCSD. Because low-cost analytic gradients at the CCSD level are now more widely available, we wanted to use this theory as the basis for a method very similar to BMC-QCISD. The new method replaces QCISD with CCSD, and replaces MP4(SDQ) with MP4(DQ). The new method, called BMC-CCSD, is illustrated in Figure 3. The four scaling coefficients are optimized for this method and are given in Table 4. The coefficients are defined by:

$$
\begin{aligned}
& E(\mathrm{BMC}-\mathrm{CCSD})=E(\mathrm{HF} / 6-31 \mathrm{~B}(\mathrm{~d}))+ \\
& c_{\mathrm{H}} \Delta(\mathrm{HF} / \mathrm{MG} 3 \mid 6-31 \mathrm{~B}(\mathrm{~d}))+c_{1} \Delta(\mathrm{MP} 2 \mid \mathrm{HF} / 6-31 \mathrm{~B}(\mathrm{~d}))+ \\
& c_{2} \Delta(\mathrm{MP} 2|\mathrm{HF} / \mathrm{MG} 3| 6-31 \mathrm{~B}(\mathrm{~d}))+c_{3} \Delta(\mathrm{MP} 4(\mathrm{DQ}) \mid \mathrm{MP} 2 / 6-31 \mathrm{~B}(\mathrm{~d}))+ \\
& c_{4} \Delta(\mathrm{CCSD} \mid \mathrm{MP} 4(\mathrm{DQ}) / 6-31 \mathrm{~B}(\mathrm{~d}))+E_{\mathrm{SO}}
\end{aligned}
$$

BMC-QCISD and the BMC-CCSD methods use both the 6-31B(d) basis set which uses Cartesian (6D) polarization functions and the MG3 basis set which uses spherical $(5 \mathrm{D}, 7 \mathrm{~F})$ polarization functions. To allow the BMC-CCSD method to be calculated using only Cartesian polarization functions, we also include the Cartesian variant BMC-CCSD-C where we replace the spherical harmonic $d$ and $f$ functions in MG3 with Cartesian (6D,10F) polarization functions. The scaling coefficients for this method are also in Table 4. 


\section{Results and discussion}

To compare the relative cost of most methods discussed, we quote the sum of the CPU times to calculate a single-point energy, single-point gradient, or single-point Hessian (as stated in each case) for the two molecules, 1-phosphinopropane and 2,2dichloro-1-ethanol, with a single $500 \mathrm{MHz}$ R14000 processor on a Silicon Graphics Origin 3800, normalized by dividing by the sum of the times for MP2/6-31G(2df,p) gradient calculations on the same two molecules with the same program on the same computer. In a few cases the times were computed on other computers but since they are normalized on the same computer on which they are computed, the times are comparable. The CPU times for CCSD gradients and Hessians were found using GAUSSIAN03, ${ }^{25}$ and all other times were calculated with the GAUSSIAN98 electronic structure package.

First we comment on the new exponent for the 6-31B(d) basis set. Table 2 shows that for 13 out of 15 cases the sp exponent is lowered. This corresponds well with previous suggestions that the valence portion the 6-31G(d) basis set is not diffuse enough. ${ }^{66,67}$ The largest change in the $d$ exponents is for $\mathrm{P}$, where the polarization function gets much tighter; this too is in agreement with a previously noted ${ }^{68}$ deficiency in the 6-31G(d) basis set. We note that the 6-31B(d) basis set, despite that fact that it was motivated by the desire to have better correlation energy balance ${ }^{11}$ in MCCM calculations, was also found to have better performance than 6-31G(d) in correlated single-level calculations by wave function theory. Thus it seems that the new basis set represents a general improvement over the 6-31G(d) basis set. Table 5 give the errors for MP2, MP4(SDQ), QCISD, and CCSD using the 6-31G(d) and 6-31B(d) basis sets. For all four methods, the errors in AEs, IPs, and EAs are decreased going to the 6-31B(d) 
basis set. Also, in all four methods the error in BHs increases slightly. The average error over Database/4, averaged over these four methods decreases $22 \%$ going to the $6-31 \mathrm{~B}(\mathrm{~d})$ basis set. The 6-31B(d) basis performs well in terms of the experimental properties calculated in the present study, but it should be used with caution for predicting any properties for which it has not been tested. We note that the exponents of the new basis functions do not follow the typical patterns found in many basis sets, such as a monotonic increase in the exponent from left to right of the periodic table.

Next we consider the performance of the new MCCM methods. Table 6 shows that BMC-QCISD has a 24\% lower average error than MC-QCISD/3. The error is lower in all categories in Table 5 when compared to MC-QCISD/3. BMC-CCSD further improves upon this and has a 27\% lower average error than MC-QCISD/3. BMC-CCSD has a lower error than MCG3/3 for EAs and BHs, and slightly higher errors for IPs and AEs. At a glance, MCG3/3 might appear obsolete, however it is still useful for those cases where one trusts the results more when they are computed by extrapolating from higher-level components; this could be the case for unusual molecules. Compared to BMC-CCSD, G3SX(MP2)//QM is much more expensive and has higher error in all four categories, while G3SX(MP3)//QM and G3SX//QM have much higher cost and slightly lower error. If we use the weighted error (which puts less emphasis on electron affinities and ionization potentials), G3SX(MP3) has 1\% lower error than BMC-CCSD, and G3SX has an error that is $15 \%$ lower. The version of BMC-CCSD where we use only Cartesian polarization functions (BMC-CCSD-C) has approximately the same errors as the version that uses spherical harmonic functions for the larger basis. 
The maximum errors (also shown in Table 6) are quite reasonable for barrier heights, electron affinities, and ionization potentials. However the maximum errors in atomization energy per bond illustrate the limited accuracy of some MCCM methods for exotic systems. BMC-CCSD underestimates the bond energy of BC by $15 \mathrm{kcal} / \mathrm{mol}$, whereas the four MCCM methods that contain at least one component calculation including triples contributions all have errors less than $5 \mathrm{kcal} / \mathrm{mol}$ for the same difficult system.

The combination of terms that comprise $\operatorname{CCSD}(\mathrm{T})$ have been shown to provide useful results for solving many chemical problems for systems including the atoms $\mathrm{H}-\mathrm{Ar}$. Although the combination of terms chosen to be included in CCSD(T) performs well for the first two rows, it can fail dramatically when applied to transition metal bonds and other systems that require a multi-reference description ${ }^{69,70}$. Similarly, one should be cautious about using MCCM methods on systems which are very different from the systems tested.

To confirm that the results are reasonable, it is instructive to examine the individual terms in the MCCM expression more closely. As an example, we present such an analysis for BMC-CCSD, although similar conclusions can be drawn for all three new methods. In Equation 9, the first, third, fifth, and sixth terms comprise the small basis set contributions to the BMC-CCSD energy, and this will be referred to as BMC-SB. In Table 6 we compare the correlation energy, singlet-triplet splitting, and electron affinity of $\mathrm{CH}_{2}$ as calculated by FCI, BMC-CCSD, and all the component calculations of BMCCCSD. Although the coefficients in BMC-CCSD are optimized to simultaneously to extrapolate both the basis set and the correlation energy, the BMC-SB energy is similar to 
the FCI/6-31B(d) energy. The BMC-SB calculated value for both the $T_{\mathrm{e}}$ and EA is very close to the $\mathrm{FCI} / 6-31 \mathrm{~B}(\mathrm{~d})$ result, although the BMC-SB result is closer to experiment in both cases. In the three systems examined, the BMC-SB correlation energy is $5.0 \% \pm$ $0.3 \%$ larger than FCI. This appears very reasonable because as mentioned before the BMC-SB group of terms includes some additional correlation energy associated with the extrapolation to complete configuration interaction. Note that the BMC-SB group of terms does not attempt to extrapolate to the FCI with the 6-31B(d) basis set. It is only part of an extrapolation to full configuration interaction with a complete basis.

As mentioned earlier in this article as well as previous work, ${ }^{6,12}$ extrapolations that include at least one component at the QCISD (or higher) level perform significantly better than those with only lower levels of correlation. A simple explanation for this can be seen by the convergence of the correlation energy for the three systems in Table 6 . Valence MP2 perturbation theory accounts for only $80 \%$ of the FCI correlation energy compared to 98\% captured by QCISD or CCSD (the latter is shown in Table 6). It is intuitively obvious then that methods using QCISD or CCSD and extrapolating the remaining $2 \%$ of the correlation energy will tend to have greater accuracy than methods attempting to extrapolate $20 \%$.

Faced with a daunting array of extrapolation procedures available, ${ }^{1-7,12,14,26,71-94}$ some researchers simply choose an additive approach to estimate a large-basis-set $a b$ initio calculation. In this approach, one performs a large basis set calculation such as MP2/MG3 and adds a high-level unscaled correlation contribution such as CCSD/6-31B(d) - MP2/6-31B(d). The sum of these two terms is an attempt to approximate a CCSD/MG3 calculation and it is equivalent to setting all the coefficients 
of the BMC-CCSD expression in Equation 9 to 1.0. For the tests in Table 6, this unscaled method has errors of 1.45 and $5.5 \mathrm{kcal} / \mathrm{mol}$ compared with the BMC-CCSD errors of 0.91 and $1.8 \mathrm{kcal} / \mathrm{mol}$. The unscaled method is far less accurate than BMCCCSD; however the cost is essentially the same. For the test in Table 5, this unscaled method has an average error of $3.89 \mathrm{kcal} / \mathrm{mol}$ and a weighted average of $3.93 \mathrm{kcal} / \mathrm{mol}$. Thus scaling is preferable to addition.

\section{Summary}

The new BMC-QCISD and BMC-CCSD methods presented in this article are shown to be very efficient new MCCM methods. The BMC-CCSD method is especially efficient, and BMC-CCSD results can be easily calculated with many electronic structure packages.

The 6-31B(d) basis set is available in several formats at the website: http://comp.chem.umn.edu/basissets, and a program, MULTILEVEL, that serves as a front

end for ACESII, ${ }^{95}$ GAMESS, $^{96}$ or GAUSSIAN ${ }^{24,25}$ to carry out the methods in Table 5 is also available on the website http://comp.chem.umn.edu/multilevel.

\section{Acknowledgment}

This work was supported in part by the U. S. Department of Energy, Office of Basic Energy Sciences. 


\section{References}

(1) Tratz, C. M.; Fast, P. L.; Truhlar, D. G. PhysChemComm 1999, 2, 14.

(2) Fast, P. L.; Corchado, J.; Sanchez, M. L.; Truhlar, D. G. J. Phys. Chem. A 1999, 103, 3139.

(3) Fast, P. L.; Sanchez, M. L.; Corchado, J. C.; Truhlar, D. G. J. Chem. Phys. 1999, 110, 11679.

(4) Fast, P. L.; Sanchez, M. L.; Truhlar, D. G. Chem. Phys. Lett. 1999, 306,

407.

(5) Curtiss, L. A.; Raghavachari, K.; Redfern, P. C.; Pople, J. A. J. Chem. Phys. 2000, 112, 1125.

(6) Lynch, B. J.; Truhlar, D. G. J. Phys. Chem. A 2003, 107, 3898.

(7) Curtiss, L. A.; Redfern, P. C.; Raghavachari, K.; Pople, J. A. J. Chem. Phys. 2001, 114, 108.

(8) Møller, C.; Plesset, M. S. Phys. Rev. 1934, 46, 618.

(9) Pople, J. A.; Head-Gordon, M.; Raghavachari, K. J. Chem. Phys. 1987, 87, 5968.

(10) Lynch, B. J.; Zhao, Y.; Truhlar, D. G. J. Phys. Chem. A 2003, 107, 1384.

(11) Gordon, M. S.; Truhlar, D. G. Int. J. Quantum Chem. 1987, 31, 81.

(12) Fast, P. L.; Truhlar, D. G. J. Phys. Chem. A 2000, 104, 6111.

(13) Gordon, M. S.; Truhlar, D. G. J. Am. Chem. Soc. 1986, 108, 5412.

(14) Fast, P. L.; Corchado, J. C.; Sanchez, M. L.; Truhlar, D. G. J. Phys. Chem. A 1999, 103, 5129.

(15) Mebel, A. M.; Morokuma, K.; Lin, M. C. J. Chem. Phys. 1995, 103, 7414.

(16) Hrusak, J.; Ten-No, S.; Iwata, S. J. Chem. Phys. 1997, 106, 7185.

(17) Boehme, M.; Frenking, G. Chem. Phys. Lett. 1994, 224, 195.

(18) Bauschlicher, C. W., Jr.; Partridge, H. J. Chem. Phys. 1995, 103, 1788.

(19) Hehre, W. J.; Radom, L.; Schleyer, P. v. R.; Pople, J. A. Ab Initio

Molecular Orbital Theory; Wiley: New York, 1986.

(20) Raghavachari, K.; Trucks, G. W.; Pople, J. A.; Head-Gordon, M. Chem. Phys. Lett. 1989, 157, 479.

(21) Knowles, P. J.; Handy, N. C. Chem. Phys. Lett. 1984, 111, 315.

(22) Knowles, P. J.; Handy, N. C. Comp. Phys. Comm. 1989, 54, 75.

(23) Werner, H.-J.; Knowles, P. J.; Lindh, R.; Schütz, M.; Celani, P.; Korona, T.; Manby, F. R.; Rauhut, G.; Amos, R. D.; Bernhardsson, A.; Berning, A.; Cooper, D. L.; Deegan, M. J. O.; Dobbyn, A. J.; Eckert, F.; Hampel, C.; Hetzer, G.; Lloyd, A. W.; McNicholas, S. J.; Meyer, W.; Mura, M. E.; Nicklass, A.; Palmieri, P.; Pitzer, R.; Schumann, U.; Stoll, H.; Stone, A. J.; Tarroni, R.; Thorsteinsson, T. MOLPRO 2002.1 Birmingham, UK, 2003.

(24) Frisch, M. J.; Trucks, G. W.; Schlegel, H. B.; Scuseria, G. E.; Robb, M. A.; Cheeseman, J. R.; Zakrzewski, V. G.; Montgomery, J. A.; Stratmann, R. E.; Burant, J. C.; Dapprich, S.; Millam, J. M.; Daniels, A. D.; Kudin, K. N.; Strain, M. C.; Farkas, O.; Tomasi, J.; Barone, V.; Cossi, M.; Cammi, R.; Mennucci, B.; Pomelli, C.; Adamo, C.; Clifford, S.; Ochterski, J.; Petersson, G. A.; Ayala, P. Y.; Cui, Q.; Morokuma, K.; Malick, D. K.; Rabuck, A. D.; Raghavachari, K.; Foresman, J. B.; Cioslowski, J.; Ortiz, J. V.; Baboul, A. G.; Stefanov, B. B.; Liu, G.; Liashenko, A.; Piskorz, P.; Komaromi, I.; 
Gomperts, R.; Martin, R. L.; Fox, D. J.; Keith, T.; Al-Laham, M. A.; Peng, C. Y.; Nanayakkara, A.; Challacombe, M.; Gill, P. M. W.; Johnson, B. G.; Chen, W.; Wong, M. W.; Andres, J. L.; Gonzalez, C.; Head-Gordon, M.; Replogle, E. S.; Pople, J. A. GAUSSIAN98; Gaussian, Inc.: Pittsburgh, PA, 2001.

(25) Frisch, M. J.; Trucks, G. W.; Schlegel, H. B.; Scuseria, G. E.; Robb, M. A.; Cheeseman, J. R.; Montgomery, J., J. A.; Vreven, T.; Kudin, K. N.; Burant, J. C.; Millam, J. M.; Iyengar, S. S.; Tomasi, J.; Barone, V.; Mennucci, B.; Cossi, M.; Scalmani, G.; Rega, N.; Petersson, G. A.; Nakatsuji, H.; Hada, M.; Ehara, M.; Toyota, K.; Fukuda, R.; Hasegawa, J.; Ishida, M.; Nakajima, T.; Honda, Y.; Kitao, O.; Nakai, H.; Klene, M.; Li, X.; Knox, J. E.; Hratchian, H. P.; Cross, J. B.; Adamo, C.; Jaramillo, J.; Gomperts, R.; Stratmann, R. E.; Yazyev, O.; Austin, A. J.; Cammi, R.; Pomelli, C.; Ochterski, J. W.; Ayala, P. Y.; Morokuma, K.; Voth, G. A.; Salvador, P.; Dannenberg, J. J.; Zakrzewski, V. G.; Dapprich, S.; Daniels, A. D.; Strain, M. C.; Farkas, O.; Malick, D. K.; Rabuck, A. D.; Raghavachari, K.; Foresman, J. B.; Ortiz, J. V.; Cui, Q.; Baboul, A. G.; Clifford, S.; Cioslowski, J.; Stefanov, B. B.; Liu, G.; Liashenko, A.; Piskorz, P.; Komaromi, I.; Martin, R. L.; Fox, D. J.; Keith, T.; Al-Laham, M. A.; Peng, C. Y.; Nanayakkara, A.; Challacombe, M.; Gill, P. M. W.; Johnson, B.; Chen, W.; Wong, M. W.; Gonzalez, C.; Pople, J. A. GAUSSIAN03, Revision B.01; Gaussian, Inc.: Pittsburgh, PA, 2004.

(26) Curtiss, L. A.; Raghavachari, K.; Redfern, P. C.; Rassolov, V.; Pople, J. A. J. Chem. Phys. 1998, 109, 7764.

(27) Curtiss, L. A.; Redfern, P. C.; Raghavachari, K.; Rassolov, V.; Pople, J. A. J. Chem. Phys. 1999, 110, 4703.

(28) Curtiss, L. A.; Raghavachari, K.; Redfern, P. C.; Pople, J. A. J. Chem. Phys. 1997, 106, 1063.

(29) Lias, S. G. Ionization Energy Evaluations. In NIST Standard Reference Database Number 69; Linstrom, P. J., Mallard, W. G., Eds.; National Institute of Standards and Technology: Gaithersburg, MD, 2003.

(30) Herzberg, K. G. Molecular Spectra and Molecular Structure. I, 2nd ed.; D. van Nostrand: Princeton, 1950.

(31) Harrington, J. E.; Weisshaar, J. C. J. Chem. Phys. 1990, 93, 854.

(32) Zhang, Z.; Kuo, S.-C.; Klemm, R. B.; Monks, P. S.; Stief, L. J. Chem.

Phys. Lett. 1994, 229, 377.

(33) Dyke, J. M.; Kirby, C.; Morris, A.; Gravenor, B. W. J.; Klein, R.; Rosmus, P. Chem. Phys. 1984, 88, 289.

(34) Kappes, M. M.; Schumacher, E. Surf. Sci. 1985, 156, 1.

(35) Chase, M. W., Jr. J. Phys. Chem. Ref. Data 1998, 9, 1.

(36) Rienstra-Kiracofe, J. C.; Tschumper, G. S.; Schaefer, H. F., III; Nandi, S.;

Ellison, G. B. Chem. Rev. 2002, 102, 231.

(37) Gutsev, G. L.; Jena, P.; Bartlett, R. J. J. Chem. Phys. 1999, 110, 2928.

(38) Villalta, P. W. Anion Photoelectron Spectroscopy of Metallic Species:

First Row Transition Metal Monocarbonyls and Aluminum Trimer, University of Minnesota, 1993.

(39) Zittel, P. F.; Lineberger, W. C. J. Chem. Phys. 1976, 65, 1236.

(40) Bauschlicher, C. W., Jr.; Langhoff, S. R.; Partridge, H. J. Chem. Phys. 1992, 96, 1240.

(41) Langhoff, S. R.; Bauschlicher, C. W., Jr. J. Chem. Phys. 1991, 95, 5882. 
(42) Martin, J. M. L.; Taylor, P. R. J. Chem. Phys. 1994, 100, 9002.

(43) Huber, K. P.; Herzberg, G. Molecular Spectra and Molecular Structure, 4: Constants of Diatomic Molecules, 1979.

(44) Sullivan, M. B.; Iron, M. A.; Redfern, P. C.; Martin, J. M. L.; Curtiss, L.

A.; Radom, L. J. Phys. Chem. A 2003, 107, 5617.

(45) Hildenbrand, D. L.; Murad, E. J. Chem. Phys. 1966, 44, 1524.

(46) Bauschlicher, C. W., Jr.; Langhoff, S. R.; Partridge, H. J. Chem. Phys.

1986, 84, 901.

(47) de Galan, L. Physica (The Hague) 1965, 31, 1286.

(48) Gurvich, L. V.; Veyts, I. V.; Alcock, C. B.; Iorish, V. S.; Editors

Thermodynamic Properties of Individual Substances;Boca Raton, FL, 1994; Vol. 3.

(49) Esseffar, M.; Luna, A.; Mo, O.; Yanez, M. J. Phys. Chem. 1994, 98, 8679.

(50) Naulin, C.; Costes, M. Chem. Phys. Lett. 1999, 310, 231.

(51) Murad, E. J. Chem. Phys. 1981, 75, 4080.

(52) Mason, M. A.; Lehmann, K. K. J. Chem. Phys. 1993, 98, 5184.

(53) Fu, Z.; Lemire, G. W.; Bishea, G. A.; Morse, M. D. J. Chem. Phys. 1990, 93, 8420.

(54) Partridge, H.; Langhoff, S. R.; Bauschlicher, C. W., Jr. J. Chem. Phys. 1988, 88, 6431.

(55) Rostas, J.; Shafizadeh, N.; Taieb, G.; Bourguignon, B.; Prisant, M. G. Chem. Phys. 1990, 142, 97.

(56) Drowart, J.; Myers, C. E.; Szwarc, R.; Vander Auwera-Mahieu, A.; Uy, O. M. Journal of the Chemical Society, Faraday Transactions 2: Molecular and Chemical Physics 1972, 68, 1749.

(57) Atkinson, R.; Baulch, D. L.; Cox, R. A.; Hampson, R. F.; Jr., K. J. A.;

Rossi, M. J.; Troe, J. J. Phys. Chem. Ref. Data 2000, 29, 167.

(58) Csaszar, A. G.; Leininger, M. L.; Szalay, V. J. Chem. Phys. 2003, 118, 10631.

(59) Jensen, P.; Bunker, P. R. J. Chem. Phys. 1988, 89, 1327.

(60) Kirkbride, F. W.; Davidson, F. G. Nature 1954, 174, 79.

(61) Ashworth, S. H.; Brown, J. M. J. Mol. Spectry. 1992, 153, 41.

(62) Lynch, B. J.; Zhao, Y.; Truhlar, D. G.

http://comp.chem.umn.edu/database, 2004.

(63) Cizek, J. Adv. Chem. Phys. 1969, 14, 35.

(64) Bartlett, R. J. J. Phys. Chem. 1989, 93, 1697.

(65) Scuseria, G. E.; Schaefer, H. F., III. J. Chem. Phys. 1989, 90, 3700.

(66) Frisch, M. J.; Pople, J. A.; Binkley, J. S. J. Chem. Phys. 1984, 80, 3265.

(67) Del Bene, J. E.; Aue, D. H.; Shavitt, I. J. Am. Chem. Soc. 1992, 114, 1631.

(68) Wesolowski, S. S.; Brinkmann, N. R.; Valeev, E. F.; Schaefer, H. F., III;

Repasky, M. P.; Jorgensen, W. L. J. Chem. Phys. 2002, 116, 112.

(69) Bauschlicher, C. W., Jr.; Partridge, H. Chem. Phys. Lett. 1994, 231, 277.

(70) Piecuch, P.; Kowalski, K.; Pimienta, I. S. O.; McGuire, M. J. Int. Rev.

Phys. Chem. 2002, 21, 527.

(71) Fast, P. L.; Sanchez, M. L.; Truhlar, D. G. J. Chem. Phys. 1999, 111, 2921. 
(72) Fast, P. L.; Schultz, N. E.; Truhlar, D. G. J. Phys. Chem. A 2001, 105, 4143.

(73) Truhlar, D. G. Basis-set extrapolation. In Chem. Phys. Lett., 1998; Vol. 294; pp 45.

(74) Brown, F. B.; Truhlar, D. G. Chem. Phys. Lett. 1985, 117, 307.

(75) Curtiss, L. A.; Raghavachari, K.; Trucks, G. W.; Pople, J. A. J. Chem. Phys. 1991, 94, 7221.

1293.

(76) Curtiss, L. A.; Raghavachari, K.; Pople, J. A. J. Chem. Phys. 1993, 98, 4192.

(77) Curtiss, L. A.; Raghavachari, K.; Pople, J. A. J. Chem. Phys. 1995, 103,

(78) Curtiss, L. A.; Raghavachari, K.; Redfern, P. C.; Baboul, A. G.; Pople, J. A. Chem. Phys. Lett. 1999, 314, 101.

(79) Curtiss, L. A.; Redfern, P. C.; Raghavachari, K.; Pople, J. A. Chem. Phys. Lett. 2002, 359, 390.

(80) Curtiss, L. A.; Redfern, P. C.; Rassolov, V.; Kedziora, G.; Pople, J. A. J. Chem. Phys. 2001, 114, 9287.

(81) Curtiss, L. A.; Redfern, P. C.; Smith, B. J.; Radom, L. J. Chem. Phys. 1996, $104,5148$.

(82) Allen, W. D.; Schuurman, M.; Wheeler, S.; Kenny, J. P.; Schaefer, H. F. "In pursuit of subchemical accuracy in computational thermochemistry"; Abstracts of Papers, 228th ACS National Meeting, Philadelphia, PA, United States, August 22-26, 2004, 2004.

(83) Gonzales, J. M.; Pak, C.; Cox, R. S.; Allen, W. D.; Schaefer, H. F., III; Csaszar, A. G.; Tarczay, G. Chemistry--A European Journal 2003, 9, 2173.

(84) Valeev, E. F.; Allen, W. D.; Hernandez, R.; Sherrill, C. D.; Schaefer, H. F., III. J. Chem. Phys. 2003, 118, 8594.

7353.

(85) Kenny, J. P.; Allen, W. D.; Schaefer, H. F., III. J. Chem. Phys. 2003, 118,

(86) Csaszar, A. G.; Tarczay, G.; Leininger, M. L.; Polyansky, O. L.;

Tennyson, J.; Allen, W. D. NATO Science Series, II: Mathematics, Physics and Chemistry 2001, 20, 317.

(87) Valeev, E. F.; Allen, W. D.; Schaefer, H. F., III; Csaszar, A. G. J. Chem. Phys. 2001, 114, 2875.

(88) Leininger, M. L.; Allen, W. D.; Schaefer, H. F., III; Sherrill, C. D. J. Chem. Phys. 2000, 112, 9213.

(89) Csaszar, A. G.; Allen, W. D.; Schaefer, H. F., III. J. Chem. Phys. 1998, 108, 9751.

(90) Schuurman, M. S.; Muir, S. R.; Allen, W. D.; Schaefer, H. F., III. J. Chem. Phys. 2004, 120, 11586.

(91) Schuurman Michael, S.; Muir Steven, R.; Allen Wesley, D.; Schaefer Henry, F., 3rd. J. Chem. Phys. 2004, 120, 11586.

(92) Martin, J. M. L.; de Oliveira, G. J. Chem. Phys. 1999, 111, 1843.

(93) Martin, J. M. L.; Uzan, O. Chem. Phys. Lett. 1998, 282, 16.

(94) Boese, A. D.; Oren, M.; Atasoylu, O.; Martin, J. M. L.; Kallay, M.; Gauss, J. J. Chem. Phys. 2004, 120, 4129. 
(95) Stanton, J. F.; Gauss, J.; Watts, J. D.; Nooijen, M.; Oliphant, N.; Perera, S. A.; Szalay, P. G.; Lauderdale, W. J.; Kucharski, S. A.; Gwaltney, S. R.; Beck, S.;

Balková, A.; Bernholdt, D. E.; Baeck, K. K.; Rozyczko, P.; Sekino, H.; Hober, C.; Bartlett., R. J. ACESII, 2004.

(96) Schmidt, M. W.; Baldridge, K. K.; Boatz, J. A.; Elbert, S. T.; Gordon, M. S.; Jensen, J. H.; Koseki, S.; Matsunaga, N.; Nguyen, K. A.; et al. J. Comp. Chem. 1993, $14,1347$. 
Table 1. Zero Point Energy (kcal/mol): Accurate Value and Values Computed Using Four Sets of Frequencies.

\begin{tabular}{lrcrrr}
\hline Molecule & $\begin{array}{c}\text { anharmonic } \\
\text { ZPE }^{a}\end{array}$ & $\begin{array}{c}\text { MP2/cc-pVDZ } \\
\text { unscaled }\end{array}$ & $\begin{array}{c}\text { MP2/cc-pVDZ } \\
\text { scaled ZPE }\end{array}$ & $\begin{array}{c}\text { exp. } \\
\text { fundamentals }{ }^{a}\end{array}$ & $\begin{array}{c}\text { scaled exp. } \\
\text { fundamentals }\end{array}$ \\
\hline $\mathrm{H}_{2}$ & 6.21 & 6.43 & 6.30 & 6.29 & 6.43 \\
$\mathrm{CH}_{4}$ & 27.71 & 28.49 & 27.89 & 27.11 & 27.69 \\
$\mathrm{NH}_{3}$ & 21.20 & 21.85 & 21.39 & 20.63 & 21.07 \\
$\mathrm{H}_{2} \mathrm{O}$ & 13.25 & 13.57 & 13.29 & 12.88 & 13.15 \\
$\mathrm{HF}$ & 5.85 & 5.96 & 5.84 & 5.92 & 6.04 \\
$\mathrm{CO}$ & 3.11 & 3.02 & 2.96 & 3.10 & 3.17 \\
$\mathrm{~N}_{2}$ & 3.36 & 3.11 & 3.04 & 3.37 & 3.44 \\
$\mathrm{~F}_{2}$ & 1.30 & 1.33 & 1.31 & 1.31 & 1.34 \\
$\mathrm{C}_{2} \mathrm{H}_{2}$ & 16.46 & 16.55 & 16.20 & 16.18 & 16.53 \\
$\mathrm{HCN}$ & 9.95 & 9.93 & 9.72 & 9.76 & 9.97 \\
$\mathrm{H}_{2} \mathrm{CO}$ & 16.53 & 16.87 & 16.52 & 16.14 & 16.48 \\
$\mathrm{CO}_{2}$ & 7.24 & 7.24 & 7.09 & 7.17 & 7.32 \\
$\mathrm{~N}_{2} \mathrm{O}$ & 6.77 & 6.74 & 6.59 & 6.70 & 6.84 \\
$\mathrm{RMSE}$ & & 0.33 & 0.17 & 0.29 & 0.10 \\
\hline
\end{tabular}

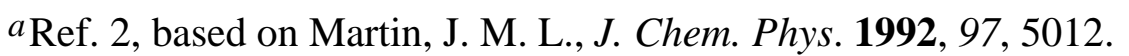

$b$ Scaling factor of 0.979

cScaling factor of 1.021 
Table 2. Spin-orbit Coupling Stabilization Energy (kcal/mol)

\begin{tabular}{llll}
\hline System & $\Delta E_{\mathrm{S}-\mathrm{O}}$ & System & $\Delta E_{\mathrm{S}-\mathrm{O}}$ \\
\hline $\mathrm{B}$ & -0.03 & $\mathrm{Cl}^{+}$ & -1.05 \\
$\mathrm{C}$ & -0.09 & $\mathrm{~B}^{-}$ & -0.02 \\
$\mathrm{O}$ & -0.23 & $\mathrm{O}^{-}$ & -0.16 \\
$\mathrm{~F}$ & -0.38 & $\mathrm{Al}^{-}$ & -0.18 \\
$\mathrm{Al}$ & -0.21 & $\mathrm{P}^{-}$ & -0.28 \\
$\mathrm{Si}$ & -0.43 & $\mathrm{~S}^{-}$ & -0.55 \\
$\mathrm{~S}$ & -0.56 & $\mathrm{CH}$ & -0.04 \\
$\mathrm{Cl}$ & -0.84 & $\mathrm{OH}$ & -0.20 \\
$\mathrm{C}^{+}$ & -0.13 & $\mathrm{NO}$ & -0.18 \\
$\mathrm{~N}^{+}$ & -0.27 & $\mathrm{FO}$ & -0.28 \\
$\mathrm{~F}^{+}$ & -0.42 & $\mathrm{SH}$ & -0.54 \\
$\mathrm{Si}^{+}$ & -0.58 & $\mathrm{ClO}$ & -0.46 \\
$\mathrm{P}^{+}$ & -0.90 & $\mathrm{Si}$ & -0.20 \\
& & & \\
\hline
\end{tabular}


Table 3. Exponential Parameters for the 6-31G(d) and 6-31B(d) Basis Sets

\begin{tabular}{llllll}
\hline & \multicolumn{2}{c}{ valence $s p$} & & \multicolumn{2}{c}{$d$-function } \\
\cline { 6 - 6 } & & & & \\
\cline { 6 - 6 } Atom & $6-31 G(d)$ & $6-31 B(d)$ & & $6-31 G(d)$ & $6-31 B(d)$ \\
& & & & & \\
$\mathrm{H}$ & $0.1612778^{a}$ & $0.139^{a}$ & & & \\
$\mathrm{Li}$ & 0.0359620 & 0.018 & & 0.200 & 0.1000 \\
$\mathrm{Be}$ & 0.0823099 & 0.060 & & 0.400 & 0.2450 \\
$\mathrm{~B}$ & 0.1267512 & 0.168 & & 0.600 & 0.4700 \\
$\mathrm{C}$ & 0.1687144 & 0.162 & & 0.800 & 0.7000 \\
$\mathrm{~N}$ & 0.2120313 & 0.180 & & 0.800 & 0.7500 \\
$\mathrm{O}$ & 0.2700058 & 0.237 & & 0.800 & 0.7200 \\
$\mathrm{~F}$ & 0.3581514 & 0.280 & & 0.800 & 1.3500 \\
$\mathrm{Na}$ & 0.0259544 & 0.013 & & 0.175 & 0.0875 \\
$\mathrm{Mg}$ & 0.0421061 & 0.048 & & 0.175 & 0.0900 \\
$\mathrm{Al}$ & 0.0556577 & 0.046 & & 0.325 & 0.1625 \\
$\mathrm{Si}$ & 0.0778369 & 0.076 & 0.450 & 0.4200 \\
$\mathrm{P}$ & 0.0998317 & 0.079 & 0.550 & 1.0600 \\
$\mathrm{~S}$ & 0.1171670 & 0.069 & 0.650 & 0.7300 \\
$\mathrm{Cl}$ & 0.1426570 & 0.092 & 0.750 & 0.6900 \\
& & & & \\
\hline
\end{tabular}

$a_{S}$ only 
Table 4. MCCM Coefficients

\begin{tabular}{lccccc}
\hline Method & $c_{\mathrm{H}}$ & $c_{1}$ & $c_{2}$ & $c_{3}$ & $c_{4}$ \\
\hline BMC-QCISD & 1.06047423 & 1.10734 & 1.33058 & 0.92517 & 1.53093 \\
BMC-CCSD & 1.06047423 & 1.09791 & 1.33574 & 0.90363 & 1.55622 \\
BMC-CCSD-C & 1.06047423 & 1.09810 & 1.34076 & 0.89040 & 1.56497 \\
\hline
\end{tabular}


Table 5. Mean Unsigned Errors (kcal/mol) for Single-Level Calculations.

\begin{tabular}{|c|c|c|c|c|c|c|c|c|c|}
\hline Quantity & Item & $\begin{array}{c}\text { MP2/ } \\
\text { 6-31G(d) }\end{array}$ & $\begin{array}{c}\text { MP2/ } \\
6-31 B(d)\end{array}$ & $\begin{array}{l}\text { MP4(SDQ)/ } \\
\text { 6-31G(d) }\end{array}$ & $\begin{array}{l}\text { MP4(SDQ)/ } \\
6-31 B(d)\end{array}$ & $\begin{array}{l}\text { QCISD/ } \\
\text { 6-31G(d) }\end{array}$ & $\begin{array}{c}\text { QCISD/ } \\
6-31 B(d)\end{array}$ & $\begin{array}{l}\text { CCSD/ } \\
6-31 G(d)\end{array}$ & $\begin{array}{c}\mathrm{CCSD} / \\
6-31 \mathrm{~B}(\mathrm{~d})\end{array}$ \\
\hline \multirow[t]{5}{*}{ MUE } & AE (Error per bond) (604) & 8.16 & 7.78 & 11.35 & 11.05 & 11.57 & 11.31 & 13.14 & 11.56 \\
\hline & Barrier heights (42) & 6.88 & 7.24 & 6.98 & 7.17 & 5.93 & 6.12 & 6.05 & 6.24 \\
\hline & Electron affinities (35) & 23.92 & 14.24 & 23.63 & 13.76 & 24.45 & 14.43 & 24.35 & 14.27 \\
\hline & Ionization potentials (36) & 11.14 & 9.71 & 10.05 & 9.16 & 9.80 & 8.85 & 9.69 & 9.06 \\
\hline & Weighted Average ${ }^{b}$ & 10.86 & 9.00 & 11.72 & 9.89 & 11.54 & 9.69 & 12.07 & 9.82 \\
\hline
\end{tabular}

${ }^{a}$ Average of rows $1,2,3$, and 4

${ }^{b}$ One third of first row plus one third of second, one sixth of third, and one sixth of fourth. 
Table 6. Mean Unsigned Errors (kcal/mol), Cost Scaling, and Single-point Costs.

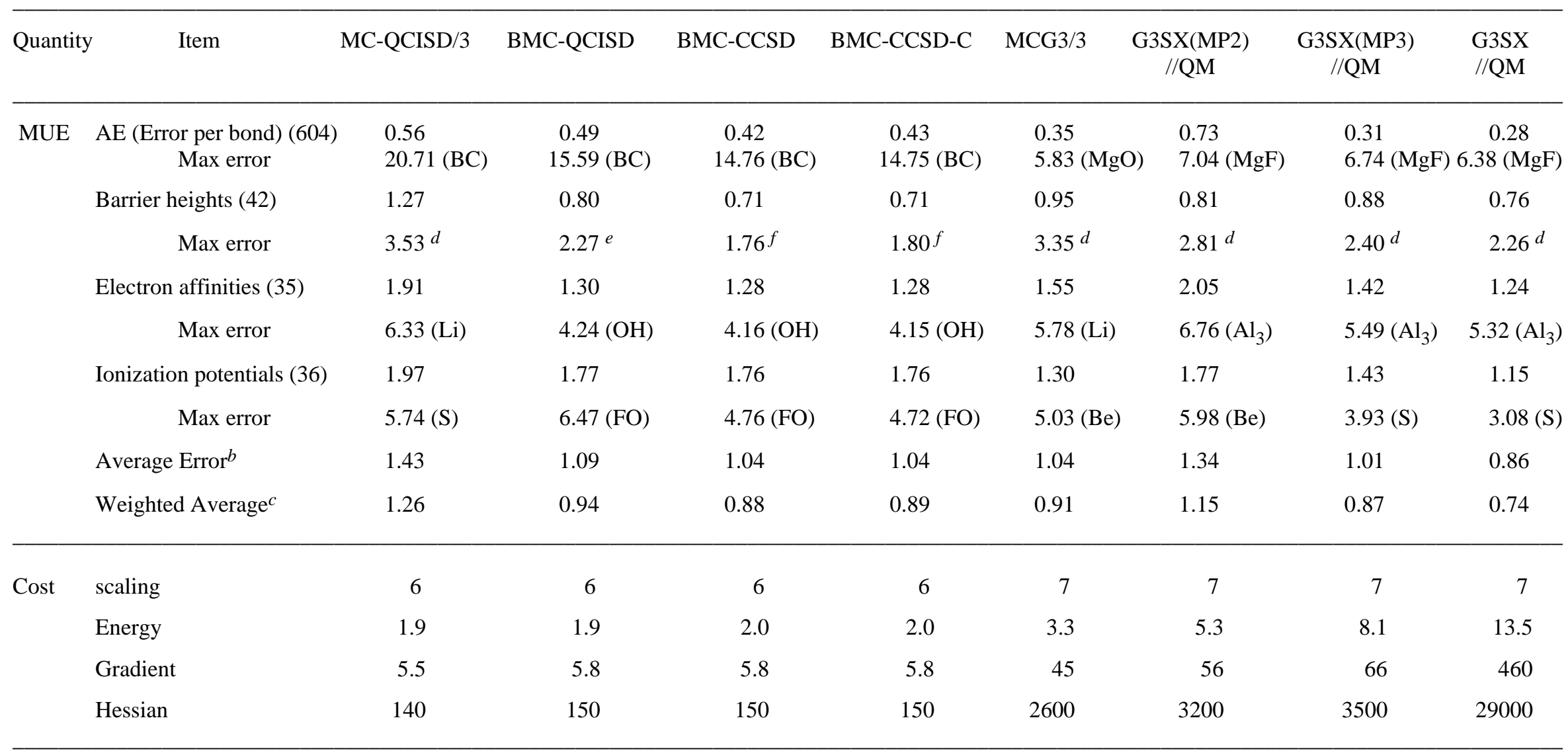

${ }^{a}$ All results in this table are for QCISD/MG3 geometries. For the three methods that are standardly defined to use other geometries, this is denoted “//QM", whereas for other methods in this table, this footnote should be sufficient.

${ }^{b}$ Average of rows $1,2,3$, and 4

${ }^{c}$ One third of first row plus one third of second, one sixth of third, and one sixth of fourth.
${ }^{d} \mathrm{PH}_{2}+\mathrm{H}_{2}$
${ }^{e} \mathrm{NH}_{2}+\mathrm{H}_{2} \mathrm{O}$
$f \mathrm{NH}+\mathrm{C}_{2} \mathrm{H}_{6}$ 
Table 7. Correlation Energy, Singlet-Triplet Splitting, and Electron Affinity of Methylene (kcal/mol)

\begin{tabular}{lccccc}
\hline Method & $\mathrm{CH}_{2}\left({ }^{3} \mathrm{~B}_{1}\right)$ & $\mathrm{CH}_{2}\left({ }^{1} \mathrm{~A}_{1}\right)$ & $\mathrm{CH}_{2}{ }^{-}\left({ }^{2} \mathrm{~B}_{1}\right)$ & $T_{\mathrm{e}}$ & EA \\
\hline HF/6-31B(d) & 0.00 & 0.00 & 0.00 & 30.20 & -41.94 \\
MP2/6-31B(d) & 52.28 & 62.30 & 70.35 & 20.18 & -23.87 \\
MP4(DQ)/6-31B(d) & 62.70 & 76.12 & 81.29 & 16.78 & -23.35 \\
CCSD/6-31B(d) & 63.68 & 78.37 & 82.29 & 15.50 & -23.33 \\
FCI/6-31B(d) & 64.84 & 80.51 & 84.18 & 14.53 & -22.60 \\
BMC-SB & & & & & \\
& 68.21 & 84.23 & 88.53 & 14.18 & -21.62 \\
HF/MG3 & & & & 28.21 & -23.56 \\
MP2/MG3 & 71.97 & 84.71 & 103.48 & 15.48 & 7.95 \\
BMC-CCSD & 94.50 & 114.15 & 132.76 & & 15.8 \\
Exp. & & & & 9.44 & 14.0 \\
\hline
\end{tabular}

$a$ Same as BMC-CCSD except $c_{\mathrm{H}}=c_{2}=0$. 


\section{Figure Captions}

Figure 1 Coefficient tree for MC-QCISD/3

Figure 2 Coefficient tree for BMC-QCISD

Figure 3 Coefficient tree for BMC-CCSD 
Figure 1.

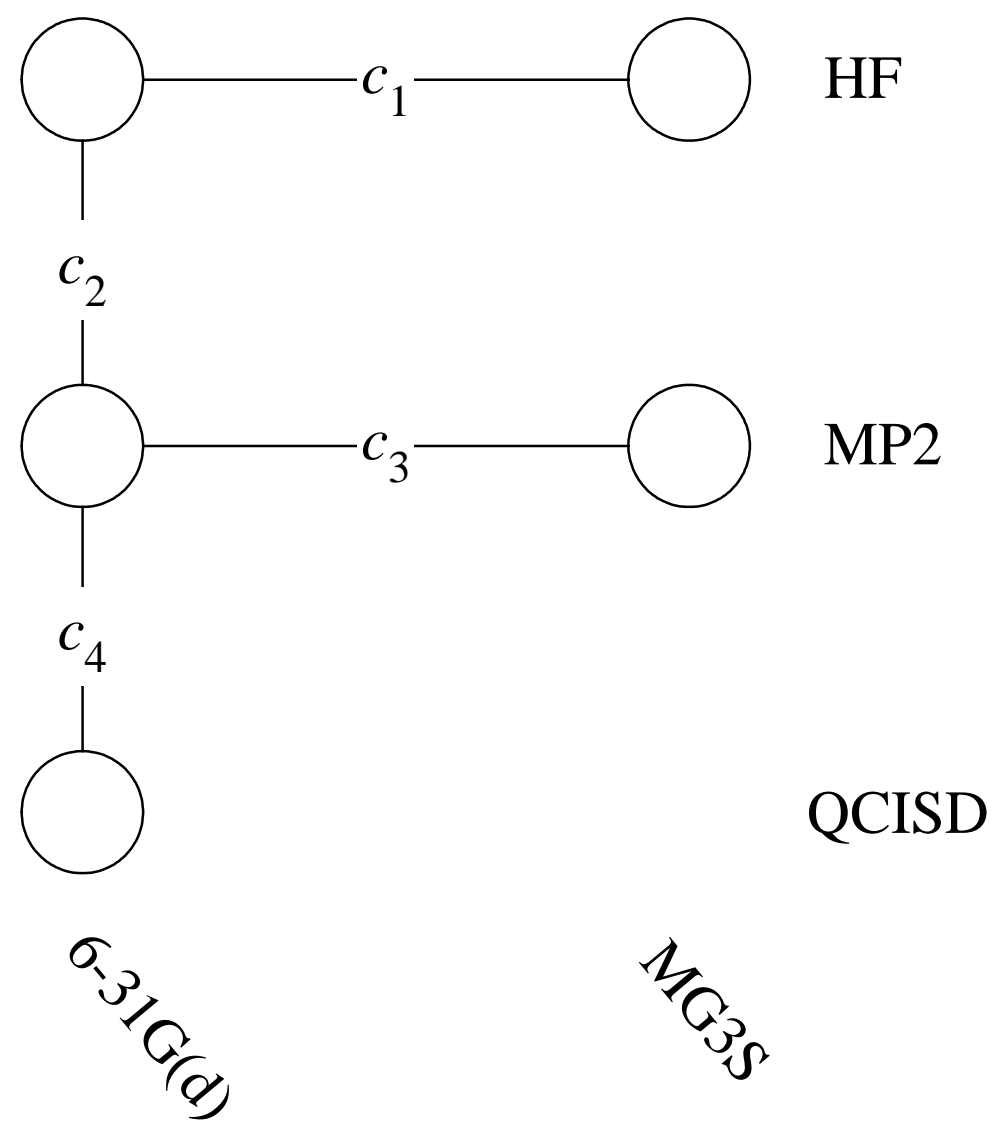


Figure 2.
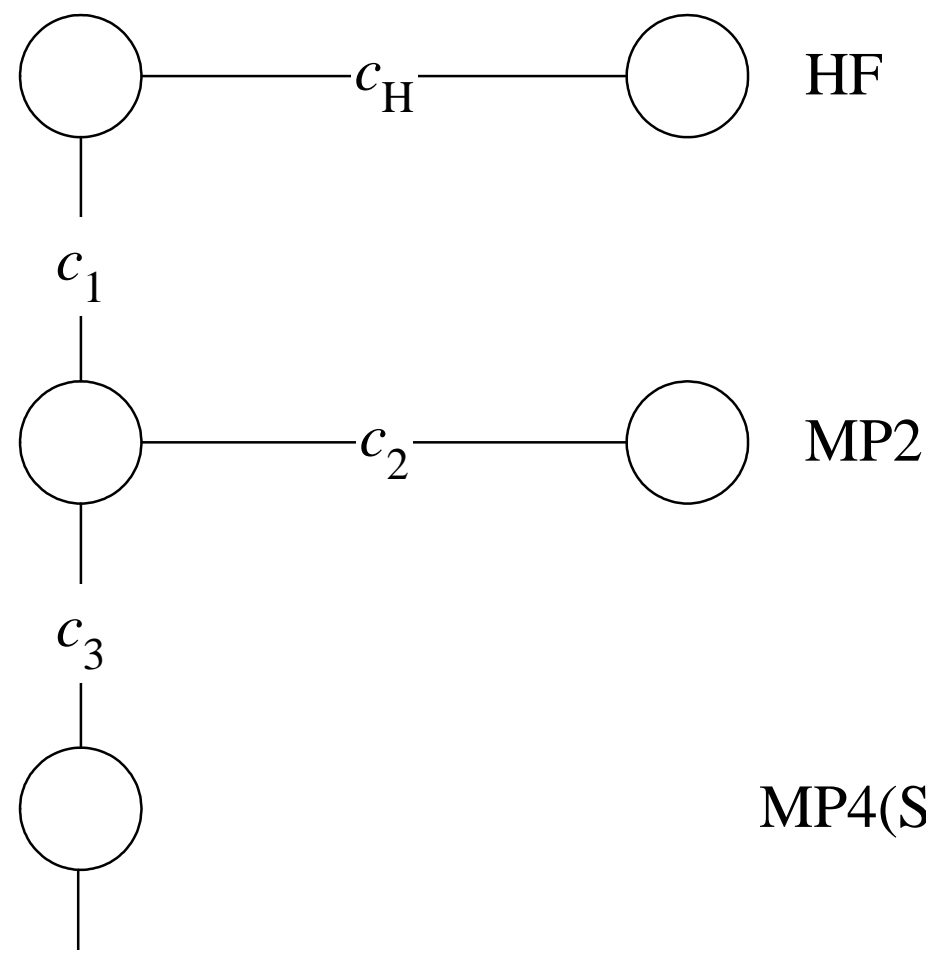

\section{MP4(SDQ)}

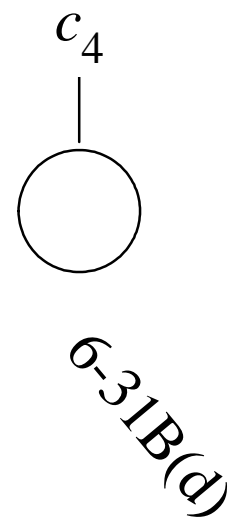

QCISD

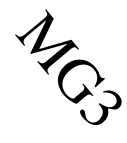


Figure 3
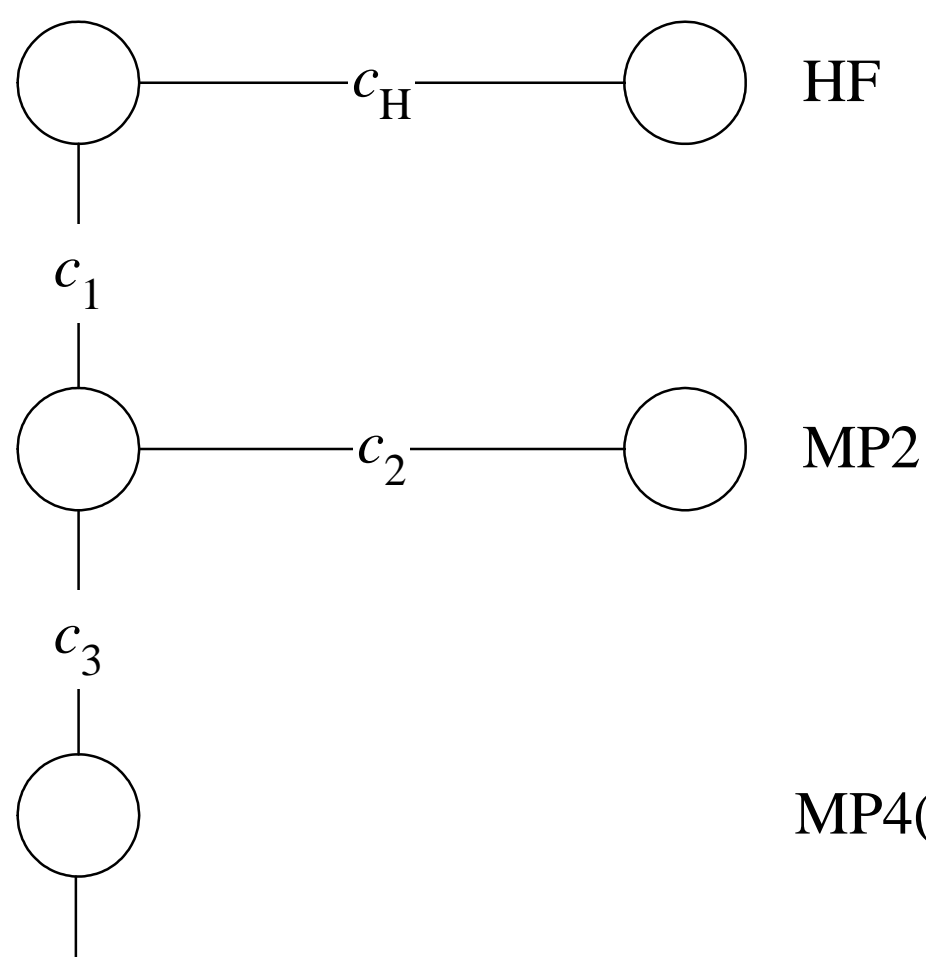

MP4(DQ)

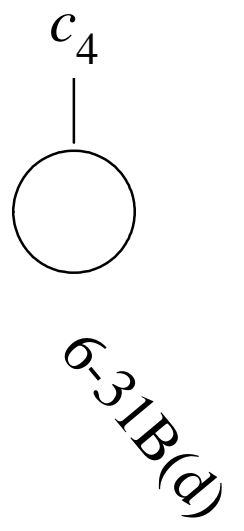

CCSD 